\title{
Income Inequality, Poverty and Food Security in West Bengal, India
}

\author{
Snehasish Karmakar \\ Department of Agricultural Extension, Agricultural Economics and Agricultural Statistics \\ Palli Siksha Bhavana, Visva-Bharati, Sriniketan-731236 West Bengal, India \\ Debashis Sarkar (Corresponding Author) \\ Department of Agricultural Extension, Agricultural Economics and Agricultural Statistics \\ Palli Siksha Bhavana, Visva-Bharati, Sriniketan-731236 West Bengal, India
}

Received: August 17, 2013 Accepted: September 15, 2013 Published: September 30, 2013

doi:10.5296/jsss.v1i1.4170 URL: http://dx.doi.org/10.5296/jsss.v1i1.4170

\begin{abstract}
The paper intends to study the nature of income inequalities, food security and poverty among different sub-groups of population in West Bengal, India. It has been found that inequalities in terms of share of total income and population exist both in case of agricultural and non-agricultural income irrespective of sub-groups. The contribution of agricultural income in the income profile is less than that of non-agricultural income which exhibits the deplorable condition of agriculture and thereby the non-agricultural sector has an immense scope for reduction of income inequality even the fact remains that about 65 per cent of the rural population engages in agriculture. The study observed that so far as food security is concerned, though India achieved self-sufficiency in food grain production since 1970s, the achievement did not percolate down to masses. These deprivations are very acute with differentiated degrees of severity in almost all sub-groups except medium farms. Inequality in income is much higher than that of food insecurity in all sub-groups which is in conformity with Engel's Law. While comparing the depth of food insecurity with poverty, it reveals that though the severity of poverty as well as food insecurity is highest in small farms, but these two do not keeping same connotations for the marginal and landless households. Hence it comes to the consequence that the severity of food insecurity not only depends on the severity of poverty but on some other factors too.
\end{abstract}

Keywords: Income inequality, Food security, Poverty, Food insecurity gap and poverty gap 


\section{Introduction}

Income inequality causes structural problems that can lead to hindrance in economic growth, food security, poverty and social unrest. Therefore, the pattern of income distribution is a matter of great concern to the economists for a long time (Clarke et al., 2003). Inequality in income distribution compels to live in poverty for a substantial portion of population. A smaller reduction of income inequality, even in absence of growth, can lead to substantial decline in poverty (Bruno et al., 1996). Poverty, inequality and food insecurity are the most crucial and persistent problems facing humanity now-a-days. Their alleviations are or at least should be at the heart of any meaningful development effort. In fact high inequality is linked with conflict and political instability because it creates incentives for people to engage in activities outside the market (e.g., illegal drug trafficking, crime) that contribute to political and social instability. Such instability generates disruptions in the current economy and uncertainty about the future, thereby discouraging the accumulation of wealth, savings and investment (Alesina \& Perotti, 1996).

Various economic, social, and political factors operating within an economy influence the distribution of income in that economy. These factors are important, particularly in developing countries, which are not only confronted with income distribution problems, but face very low per capita incomes and declining food consumption. Many economists have emphasized the importance of economic growth in conjunction with investing to increase the productivity of the agriculture sector and promoting human capital development. They believed that investing in these areas should stimulate economic growth and raise the incomes of the poor relatively faster than other income groups. It will also lead to the reduction of poverty and increase access to food, thereby reducing the main cause of chronic under nutrition (Peters et al., 1997).

Food security is one dimension of poverty, assessing whether a household can meet its food needs and its vulnerability to shocks. Therefore, it can be stated that food insecurity, poverty, malnutrition, income inequality and lack of decent employment opportunities reinforce each other in a vicious cycle by eroding human capital and decreasing labour productivity, thereby perpetuating poverty and social inequalities across generations. Therefore, creating new jobs and upgrading the quality of existing ones, particularly in rural areas, should be a core pillar of any development strategy addressing the global hunger challenge (FAO, 2006).

In the decades of 80's and 90's the growth rate of food grains had outstripped that of population in West Bengal. It is, therefore, obvious that there should not be poverty in the state. But in reality, this is not true. There may be number of reasons behind it viz., wastages of food, uneven distribution of food and insufficient purchasing power in the hands of the poor people (Konar, 2001). Though the food availability in India might be described today as state of plenty, but often starvation death news occurs. Production surplus does not essentially indicate equivalent food availability, as good numbers of people do not have enough money to buy food (Verma, 2006). The spectacular agricultural growth on income distribution in rural West Bengal during the 1980s and early 1990s revealed that during 1983 to 1993-94, when agricultural output in West Bengal was growing at an unprecedented rate, the degree of inequality in the distribution of rural consumption expenditure declined significantly. However, during the later part of 1990s, when the rate of growth of agricultural output 
declined substantially, its impact on rural income distribution was reversed, with deceleration in the rate of growth of rural employment and average earning of the agricultural labour households. Thus income distribution in rural West Bengal favoured the poorer classes of population or marginal and small farmers during the period of impressive agricultural growth. But neither the agricultural growth nor the favourable change in rural income distribution could be sustained in the following period (Chattopadhyay, 2005).

Under this background, an attempt has been made to study the nature of income inequalities, food security and poverty among different sub-groups of population. This study intends to fulfil three specific objectives. First is to access the present status of inequality in terms of household individual income and their food security in rural areas. Second is to measure the poverty gap along with the poverty line as well as food gap from the minimum food requirement to attain food security and third to compare income inequality with severity of poverty and food insecurity.

\section{Data Base and Methodology}

The study has been conducted based on primary data collected by personal interview with the help of pre-tested household schedule. There are 19 districts in West Bengal including Kolkata and Birbhum is one of the important districts in sub-humid laterite belt of West Bengal. Birbhum district in West Bengal has been purposively selected for the present study because the majority of the population ( 91.42 per cent) live in rural areas and the intra-district imbalances with respect to the agro-technological and developmental parameters are very prominent in this district. Similarly in general phenomenon, education leads to development. The incidence of rural poverty is still quite high in Birbhum even in spite of comparatively higher rural literacy rate (59.9 per cent) as per Census (2001) than that of other districts in West Bengal.

The primary data for the study has been collected through a multi-stage stratified random sampling method. There are three sub-divisions in the district viz., Bolpur-Sriniketan, Rampurhat and Suri. In the first stage, all three sub-divisions have been selected purposively to cover the entire district. In the second stage, one block from each sub-division has been selected randomly. From each block 4 villages have been selected randomly. In the fourth stage, the list of households of these selected villages has been collected and ultimately 25 per cent of the households of these villages belonging to different size-classes have been selected randomly. In total 300 households have been selected from over 12 villages as sample unit of the study. The selected households have been sub-divided into various categories based on size of land holdings. These are Marginal (below 1.0 ha), Small (1.0-2.0 ha), Medium (2.0 - 10.0 ha), Large (above $10.0 \mathrm{ha}$ ) and landless households. In the study area, marginal, small and medium farms are farms for whom farming is one of the major livelihood activities, yet who have other non-agricultural occupations. Thus the income profile is sub-divided basically into two categories i.e. agriculture and non-agriculture. Agricultural income relates to those who have operated land. Net return from agriculture is considered as agricultural income, whereas income from all sources other than agriculture is considered as non-agricultural income.

It is pertinent to mention that the income of a household has been calculated based on the money value, either earned in monetary unit or in kind during the reference year 2007-08. 
The per capita food energy intake has been taken as a measure of food security. Therefore, to calculate the total food energy intake by a household, the quantity of different food items consumed by the households is converted into energy value as per the unit ratio shown in the consumer expenditure schedule for NSS $50^{\text {th }}$ Round, 1993-94. To get the per capita per day energy intake by a member of a household, the aggregate food energy intake per day is divided by total 'consumer unit' of the household. A 'consumer unit' as defined in National Sample Survey (NSS), is a normal male person doing sedentary work and belonging to the age group 20-39 years is taken as one unit and the other coefficients are worked out on the basis of calorie requirement. The Report on the State of Food Insecurity in Rural India prepared jointly by United Nations World Food Programmes (WFP) and MS Swaminathan Research Foundation (MSSRF) used a cut-off point of 1,890kcal per consumer unit per day. Consequently, a household is considered as food secured if a consumer unit, on the average, intake more than $1890 \mathrm{kcal}$ of food per day.

The technique of Mixed Recalled Period has been used as followed by NSSO in order to collect the quantities of food consumed by a household, The food-data are collected on major items comprising rice, wheat, pulses, biscuits, edible oils, vegetables, meat, egg, fish, fruits, milk and milk products, acquired by households including food purchases, foods consumed from their own farms or gardens and foods received in kind.

In India, poverty and poverty lines are generally defined as the per-capita monetary requirements an individual needs to afford for purchase of a basic bundle of goods and services. The value of this basic basket of goods and services can be determined in many ways e.g. absolute poverty line, relative poverty line. We are interested here with the absolute poverty line which is anchored to maintain minimum nutritional support that produces energy of 2,400 kcals and 2,100 kcals per capita per day respectively in rural and urban areas. The official estimates of poverty line of Planning Commission, Government of India vary over time and across states. The Expert Group on Estimation of Proportion and Number of Poor (EGEP), based on NSS data of $61^{\text {st }}$ Round (2004-05), has estimated the rural poverty line in West Bengal as Rs. 382.82 per capita per month using Mixed Recall Period (MRP)- 30 days for frequently used consumption goods and 365 days for infrequently used consumption goods. Therefore, the poverty line of Rs. 383 per capita per month has been taken as operational Poverty Line in the present study.

Three different measures of poverty that capture its percentage of incidence, depth and severity have been considered in this study. These three measures are the Head Count Ratio (HCR), the Poverty Gap (PG), and the Squared Poverty Gap (SPG). By far the most widely-used measure is the headcount index, which simply measures the proportion of the population that is counted as poor, often denoted by $\mathrm{P}_{0}$. Formally,

$$
\mathrm{P}_{\mathrm{o}}=\frac{\mathrm{N}_{\mathrm{p}}}{\mathrm{N}}
$$

Where, $\mathrm{Np}$ is the number of poor and $\mathrm{N}$ is the total population (or sample). If 60 people are poor in a survey that samples 300 people, then $\mathrm{P}_{0}=60 / 300=0.2=20 \%$. For reasons that will be clearer below, it is often helpful to rewrite as 


$$
\mathrm{P}_{0}=\frac{1}{N} \Sigma \mathrm{I}(\mathrm{y}<\mathrm{z})
$$

Here, I (-) is an indicator function that takes on a value of 1 if the bracketed expression is true, and 0 otherwise. So if income $\left(\mathrm{y}_{\mathrm{i}}\right)$ is less than the poverty line $(z)$, then I (-) equal to 1 and the household would be counted as poor.

It is fact that the poverty and the food insecurity measurements do not take the intensity or severity into account. To measure the severity of poverty/food insecurity we need to measure the poverty gap/food insecurity gap. It is the mean shortfall from the poverty line (counting the non-poor as having zero shortfalls) as a percentage of the poverty line concerned. More specifically, define the poverty gap (Gi) as the poverty line (z) less actual income (yi) for poor individuals; the gap is considered to be zero for everyone else. Using the index function, we have

$$
\mathrm{Gi}=(\mathrm{z}-\mathrm{yi}) . \mathrm{I}(\mathrm{yi}<\mathrm{z}) .
$$

Then the poverty gap index $(P l)$ may be written as

$$
\mathrm{P}_{1}=\frac{1}{N} \sum_{i=1}^{N} \frac{\mathrm{G}_{i}}{\mathrm{z}}
$$

Similarly, food insecurity gap is measured by the same function, where $\mathrm{z}$ is the minimum energy requirement (which is $1890 \mathrm{kcal}$ per day per consumer unit in rural India according to United Nations WFP and MSSRF) and yi is the actual intake of energy derived from food consumption for food unsecured individual; the gap is considered to be zero for food secured individual.

Squared poverty gap index (SPG), another measure of intensity of poverty, is the average of the squared poverty gap as a proportion of the poverty line, where the poverty gap is as defined as for the PG index. Formally defined as:

$$
\mathrm{P}_{2}=\frac{1}{N} \sum_{i=1}^{W}\left(\frac{G_{1}}{z}\right)^{2}
$$

This index can also be extended for food insecurity too. Both the gap indices are sensitive to inequality in distribution of income amongst the poor and in distribution of food stuff amongst the food unsecured.

These measures are indicators of the potential saving to the poverty/food insecurity alleviation budget from targeting: the smaller is the gap index, the greater the potential economies for poverty/food insecurity alleviation budget from identifying the characteristics of the poor/food unsecured - using survey or other information - so as to target benefits and programs.

To access the present status of inequality in terms of household income and food security in the district the Gini Coefficient, as used by Lerman and Yitzhaki (1985) was estimated that has a score of 1 indicating perfect inequality and a score of 0 indicating perfect equality by different size-class. The formula is: 


$$
G=\frac{2}{\bar{y}} \operatorname{cov}(y, F(y))
$$

Where $\mathrm{y}$ is the income/ intake energy value of food, $F(y)$ is the cumulative distribution function of income/ intake energy value of food and Cov is covariance.

\section{Results and Discussion}

\subsection{Inequality in Income and Food Security}

Even in spite of sectoral development, the relevant inequalities take different forms, relating not only to large disparities of income but also to other bases of advantage such as food security, expenditure on food etc. In so far as it has been concentrated on the standard economic inequalities, perhaps because these inequalities are particularly conspicuous, and lend themselves to convenient measurement. In reality, inequalities are extreme in almost all surveyed villages with different spheres as well as within and between sub-groups. Table 1 portrays the status of income inequalities by different sub-groups. Inequality in the share of population and income exhibits that the marginal farms constituting 31.33 per cent of the total population whereas the share is only 26.04 per cent, in which 1.36 per cent generates from agriculture and 24.68 per cent from non-agriculture sources (Table 1). On the contrary, as per the share of income, small ( 9.00 per cent) and medium (2.67 per cent) farms enjoy 9.90 per cent and 10.32 per cent, respectively. The most interesting feature is that the landless households gain 53.74 per cent of total income even they constitute more than half of total population. It is also pertinent to note that in spite of agriculture being the main livelihood, the contribution of this sector (5.62 per cent) in the income profile is absolutely poor than that of non-agricultural source ( 94.38 per cent) which exhibits the deplorable condition of agriculture and thereby the non-agricultural sector has an immense scope for reduction of income inequality even the fact remains that about 65 per cent of the rural population engages in agriculture.

Table 1. Size-class inequality in the share of population and income

\begin{tabular}{ccccc}
\hline Category & Share in population (\%) & \multicolumn{3}{c}{$\begin{array}{c}\text { Share in income (\%) } \\
\text { Agricultural income }\end{array}$} \\
\cline { 3 - 5 } Non-agricultural income & Total income \\
\hline Marginal & 31.33 & 1.36 & 24.68 & 26.04 \\
Small & 9.00 & 1.69 & 8.21 & 9.90 \\
Medium & 2.67 & 2.57 & 7.75 & 10.32 \\
Land less & 57.00 & - & 53.74 & 53.74 \\
Over all & 100.00 & 5.62 & 94.38 & 100.00 \\
\hline
\end{tabular}

Source: Field survey.

Note: Based on household income.

Gini indices in regards to per capita income inequality among different sub-groups show that these are highest in marginal (0.5163) followed by small (0.4982) and medium (0.4086) farms (Table 2). The inequality in agricultural income relates to all sub-groups is low as compared to their counterparts. The inequality in income relates to agriculture is lowest in small farms (0.0027) and highest in medium farms (0.0655). The most vulnerable feature is 
that the overall income inequality is very acute $(0.4295)$.

Table 2. Size-class income inequality by income sources

\begin{tabular}{cccc}
\hline Category & Total income & Agricultural income & Non-agricultural income \\
\hline Marginal & $0.5163(100.00)$ & $0.0036(0.70)$ & $0.5127(99.30)$ \\
Small & $0.4982(100.00)$ & $0.0027(0.54)$ & $0.4955(99.46)$ \\
Medium & $0.4086(100.00)$ & $0.0655(16.03)$ & $0.3431(83.97)$ \\
Land less & $0.3186(100.00)$ & - & $0.3186(100.00)$ \\
Over all & $0.4295(100.00)$ & $0.0106(2.47)$ & $0.4189(97.53)$ \\
\hline
\end{tabular}

Source: Field Survey.

Note: (1) Figures in the brackets indicates percentage to total, (2) Based on per capita income.

The monthly per capita income and expenditure on food in case of medium size class is highest in absolute terms and lowest in percentage terms. Mean income is lowest in marginal (Rs. 533.08) followed by small (Rs. 580.45) and landless households (Rs. 644.95). On the contrary, the mean food expenditure is lowest (Rs. 352.63) in landless followed by marginal and medium sub-groups. In case of food expenditure as a percentage to monthly income, landless household exhibits 54.68 per cent preceded by small (73.93 per cent) and marginal farms (76.69 per cent) (Table 3). The point to recognize is that 59.67 per cent of monthly income, on an average, for the consumption of food is far more delicate and widespread than the explicit stories of poverty in rural economy.

Table 3. Size-class income and food expenditure inequality

\begin{tabular}{|c|c|c|c|c|c|}
\hline \multirow{2}{*}{ Size-class } & \multicolumn{2}{|c|}{ Mean (Rs.) } & \multicolumn{2}{|c|}{ Median (Rs.) } & \multirow{2}{*}{$\begin{array}{c}\text { Food expenditure (\% to } \\
\text { monthly income) }\end{array}$} \\
\hline & Income & Food expenditure & Income & Food expenditure & \\
\hline Marginal & 533.08 & 408.80 & 339.17 & 377.13 & 76.69 \\
\hline Small & 580.45 & 429.14 & 335.07 & 404.42 & 73.93 \\
\hline Medium & 1988.36 & 936.01 & 1839.03 & 964.13 & 47.07 \\
\hline Landless & 644.95 & 352.63 & 522.92 & 341.20 & 54.68 \\
\hline Overall & 639.91 & 381.85 & 462.50 & 350.88 & 59.67 \\
\hline
\end{tabular}

Source: Field survey.

Note: Based on per capita individual.

\subsection{Poverty and Food Insecurity Gaps}

We can take a closer look at this whole issue by examining the poverty and food insecurity gaps. Table 4 shows that food is secured in medium ( 100.00 per cent) followed by small farms ( 96.30 per cent). Food is also secured at the tune of 80 per cent of marginal and 
landless households. These figures strengthen the fact that there is a positive relationship between the size of landholding and food security.

Table 4. Size-class distribution of food security

\begin{tabular}{cccc}
\hline Size-class & Food secured & Food unsecured & Total \\
\hline Marginal & 78.72 & 21.28 & 100.00 \\
Small & 96.30 & 03.70 & 100.00 \\
Medium & 100.00 & 00.00 & 100.00 \\
Landless & 78.95 & 21.05 & 100.00 \\
Overall & 80.33 & 19.67 & 100.00 \\
\hline
\end{tabular}

Source: Field surveys.

Regarding food security, marginal farms show highest degree of inequality (0.1429) followed by landless households (0.1100) and medium (0.0994) though the small farms are of lowest inequality $(0.0760)$. It is interesting to note that the inequality in income is much higher than that of food security irrespective of different size-classes (Table 5).

Table 5. Size-class income and food security Gini

\begin{tabular}{lcc}
\hline Size-class & Income Gini & Food security Gini \\
\hline Marginal & 0.5163 & 0.1429 \\
Small & 0.4982 & 0.0760 \\
Medium & 0.4086 & 0.0994 \\
Landless & 0.3186 & 0.1100 \\
Overall & 0.4295 & 0.1218 \\
\hline
\end{tabular}

Source: Field survey.

It is fact that the low incidence of poverty (Table 6), despite the intervening crisis of economic growth, suggests that the various policies and programmes adopted in the process of economic development have helped the rural poor and other available evidence also supports this view too. The incidence of BPL households which reflects the economic conditions of rural households has been found to be lower than that of APL as a whole. In the year under review, the severity of poverty decreases with the increase in farm sizes (Table 7). These trends are consistent and the economic growth led to the improvements in general living standards of rural people during this period. Food insecurity exists in rural areas except medium farms. The severity of which is highest amongst the small $\left(\mathrm{F}_{1}=0.155\right)$ followed by landless $\left(F_{1}=0.136\right)$ and marginal $\left(F_{1}=0.087\right)$ households resulting to overall gap of 0.121 (Table 8). While comparing food insecurity gap with poverty gap, it reveals that though the severity of poverty as well as food insecurity is highest in small farms, but these two do not 
keeping same connotations for the marginal and landless households. Hence it comes to the consequence that the severity of food insecurity not only depends on the severity of poverty but on some other factors too, which needs to be further analysed.

Table 6. Size-class percentage distribution of APL/BPL in rural Birbhum

\begin{tabular}{cccc}
\hline Size-Class & BPL & APL & Total \\
\hline Marginal & 19.67 & 11.67 & 31.33 \\
Small & 5.33 & 3.67 & 9.00 \\
Medium & 0.00 & 2.67 & 2.67 \\
Landless & 20.33 & 36.67 & 57.00 \\
Overall & 45.33 & 54.67 & 100.00 \\
\hline
\end{tabular}

Source: Field survey.

Table 7. Size-class poverty gap indices

\begin{tabular}{ccc}
\hline Size-Class & Poverty $\operatorname{Gap} \operatorname{Index}\left(\mathrm{P}_{1}\right)$ & Poverty $\operatorname{Gap} \operatorname{Index}\left(\mathrm{P}_{2}\right)$ \\
\hline Marginal & 0.49 & 0.32 \\
Small & 0.53 & 0.32 \\
Medium & 0.00 & 0.00 \\
Landless & 0.29 & 0.11 \\
Overall & 0.41 & 0.22 \\
\hline
\end{tabular}

Source: Field survey.

Table 8 . Size-class food insecurity gap indices

\begin{tabular}{ccc}
\hline Size-class & Food Insecurity Gap index $\left(\mathrm{F}_{1}\right)$ & Squared Food Insecurity Gap index $\left(\mathrm{F}_{2}\right)$ \\
\hline Marginal & 0.087 & 0.012 \\
Small & 0.155 & 0.024 \\
Medium & 0.000 & 0.000 \\
Landless & 0.136 & 0.029 \\
Overall & 0.121 & 0.023 \\
\hline
\end{tabular}

Source: Field survey.

The comparative study of income inequality to the incidence of poverty and food security can be gauged through the different sub-groups (Table 9). The marginal have highest degree of income inequality $(0.5163)$ which is followed by small $(0.4982)$ farms. As a result, the percentage of the population living below the poverty line (62.78) is highest in marginal 
followed by small (59.22) farms with the excluding landless. The percentage of food insecurity ( 21.28 per cent) is also highest in marginal followed by small ( 0.37 per cent). Hence, it may not be outplace to note that the higher is inequality in income distribution, the higher is the incidence of poverty and food insecurity. Similarly as the size of the land holding increase the incidence of poverty as well as the food insecurity decreases. However, the severity of poverty and food insecurity, measured by poverty gap index $\left(\mathrm{P}_{1}\right)$ and food insecurity gap index $\left(\mathrm{F}_{1}\right)$ respectively, is highest in small and there are absent in medium farms. So, it is plausible to think that the severity of poverty and food insecurity may not depend on the size of land holding itself, but at the same time this notion paves the ways for further analysis with sophisticated statistical tools. As regard the landless households, the incidence and severity of poverty is less than that of overall households, but the incidence and severity of food insecurity is above the overall ones though their income inequality is below the overall average.

Table 9. Size-class income inequality, poverty and food insecurity

\begin{tabular}{cccccc}
\hline Size-class & $\begin{array}{c}\text { Income Gini } \\
\text { index }\end{array}$ & HCR & $\begin{array}{c}\text { Percentage of food } \\
\text { insecurity }\end{array}$ & $\begin{array}{c}\text { Poverty Gap }\left(\mathrm{P}_{1}\right) \\
\text { index }\end{array}$ & $\begin{array}{c}\text { Food insecurity gap } \\
\left(\mathrm{F}_{1}\right) \text { index }\end{array}$ \\
\hline Marginal & 0.5163 & 62.78 & 21.28 & 0.49 & 0.087 \\
Small & 0.4982 & 59.22 & 03.70 & 0.53 & 0.155 \\
Medium & 0.4086 & 0.00 & 00.00 & 0.00 & 0.000 \\
Landless & 0.3186 & 35.67 & 21.05 & 0.29 & 0.136 \\
Overall & 0.4295 & 46.00 & 19.67 & 0.41 & 0.121 \\
\hline
\end{tabular}

Source: Field survey.

\section{Conclusions, Policy Implications And Suggestions}

Economic policies especially with regards to rural development have undergone much change over the last few years in India, and more change are in the process of being implemented. The debate surroundings these reforms has mobilized enormous attention and energy, and the arguments presented on each side have been quite forceful and firm, even acrimonious. These debates however can help to promote human capabilities, and, given the imperative need for rapid elimination of endemic deprivation. If we closely go through the above findings, it comes out to the point that the inequalities in terms of share of total income and population exist both in case of agricultural and non-agricultural income irrespective of sub-groups. The contribution of agricultural income in the income profile is less than that of non-agricultural income which exhibits the deplorable condition of agriculture and thereby the non-agricultural sector has an immense scope for reduction of income inequality even the fact remains that about 65 per cent of the rural population engages in agriculture.

So far as food security is concerned, though India achieved self-sufficiency in food grain production since 1970s, the achievement did not percolate down to masses. These deprivations are very acute with differentiated degrees of severity in almost all sub-groups 
except medium farms. Inequality in income is much higher than that of food insecurity in all sub-groups which is in conformity with Engel's Law.

While comparing the depth of food insecurity with poverty, it reveals that though the severity of poverty as well as food insecurity is highest in small farms, but these two do not keeping same connotations for the marginal and landless households too. Hence it comes to the consequence that the severity of food insecurity not only depends on the severity of poverty but on some other factors.

The deplorable condition of agriculture can be improved by adopting area specific technologies and the field level constraints for adoption of improved technologies can be removed through bottom-up approach. Strengthening the Training and Visit Extension (T\&V) as advocated by World Bank experts Benor et al. (1984) may be the other alternative to wipe out the field level constraints in a realistic way.

There is growing consensus that creating rural employment, reducing inequality, defeating poverty and attaining food security can only happen through a new growth path founded on a restructuring of the Indian economy to improve its performance in terms of rural labour absorption as well as the composition and rate of growth. To achieve that step change in growth and transformation of economic conditions requires hard choices and a shared determination as Indians to see it through. Therefore, it is imperative to forging such a consensus and leading the way by

1. Identifying areas where rural employment creation is possible on a large scale as a result of substantial changes in conditions.

2. Developing a policy package especially for rural areas to facilitate employment creation, above all through:

a. A comprehensive drive to enhance both economic equality and development of agriculture;

b. Systemic changes to mobilise domestic investment around activities that can create sustainable rural employment; and

c. Strong social dialogue to focus all stakeholders on encouraging growth in rural employment (both agriculture and non-agriculture) creating activities.

\section{References}

Alesina, A., \& Perotti, R. (1996). Income distribution, political instability and investment. $\begin{array}{llll}\text { European Economic } & \text { Review, } & \text { 40(6), } & \text { 1203-1228. }\end{array}$ http://dx.doi.org/10.1016/0014-2921(95)00030-5

Benor, D., \& Baxter, Ml. (1984). Training and Visit Extension. World Bank Publications 1818 1 H Street, N.W. Washington D.C. 20433, USA.

Bhalla, G. S., \& Singh, G. (1997). Recent development in Indian agriculture: A state level analysis. Economic and Political Weekly, 32(13), A2-A18.

Bhattacharya, Pranab Kumar. (2007). 25 years of West Bengal economy. In Raj Kumar Sen and Asis Dasgupta (Eds.), West Bengal Today - 25 years of Economic Development. Deep and Deep Publications Pvt. Ltd., New Delhi.

Bruno, Michael, Martin Ravillion, \& Lyn Squire. (1996). Equity and growth in developing 
countries: Old and new perspectives on the policy issues. Policy Research Working Paper, No. 1563. The World Bank. Washington, D.C.

Chattopadhyay, Apurba Kumar. (2005). Distributive impact of agricultural growth in rural West Bengal. Economic and Political Weekly, 40(53), 5601-5610.

Clerke, G. L., \& Colin, X. H. Zon. (2003). Finance and income inequality: Text of alternative theories. World Bank Policy Research Working Paper 2984, Washington D.C., World Bank.

FAO. (2006). Inequality Analysis The Gini Index, EASYPol Module 040. Retrieved from http://www.fao.org/tc/easypol.

Government of India. (1989). Results on Per Capita and Per Consumer Unit Per Diem Intake of Calorie, Protein and Fat and Perceptions of the People on Adequacy of Food. Sarvekshana, 13(2).

Government of India. (1993). Report of the Expert Group on Estimation of Proportion and Number of Poor. Perspective Planning Division, Planning Commission, New Delhi.

Government of India. (1996). Nutritional Intake in India NSS 50th Round July 1993-June 1994 Fifth Quinquennial Survey on Consumer Expenditure. Report No. 405, National Sample Survey Organisation, Department of Statistics, New Delhi.

Government of India. (2007a). Public Distribution System and Other Sources of Household Consumption 2004-2005, Volume I, NSS 61st Round (July 2004- June 2005). Report No. $510(61 / 1.0 / 3)$, National Sample Survey Organisation, Ministry of Statistics and Programme Implementation, New Delhi.

Government of India. (2007b). Poverty Estimates for 2004-05, Press Information Bureau, New Delhi, India.

Konar, D. N. (2001). Production of food grains in West Bengal: The scenario of the post liberalization decade. Economic Affairs, $46\left(4^{\text {th }}\right.$ qtr. $)$.

Pal, P. (2007). Development pattern in West Bengal since 1980s. In Raj Kumar Sen and Asis Dasgupta (Eds.), West Bengal Today - 25 years of Economic Development. Deep and Deep Publications Pvt. Ltd., New Delhi.

Peters, M. M., \& Shapouri, Shahla. (1997). Income inequality and food security. In Food Security Assessmernts - Situation and outlook series. International Agriculture and Trade Report.

Rawal, V., \& Swaminathan, M. (1998). Changing Trtajectories: Agricultural Growth in West Bengal: 1950 to 1996. Economic and Political Weekly, 33(40), 2595-2602.

Sawant, S. D., \& Achuthan, C. V. (1995). Economic growth across crops and regions: Emerging trends and patterns. Economic and Political Weekly, 30(2).

Suryanarayana, M. H. (1995). Growth, poverty and levels of living: hypotheses, methods and policies. Journal of Indian School of Political Economy, 7(2).

Suryanarayana, M. H. (1996). Food security and calorie adequacy across states: implications for reform. Journal of Indian School of Political Economy, 8(2).

Suryanarayana, M. H. (1997). Food security in India: Measures, norms and issues. Development and Change, 28(4), 771-789. http://dx.doi.org/10.1111/1467-7660.00064

Verma, Prasoon. (2006). Agriculture as an industry. Yojana. 50(9). 


\section{Copyright Disclaimer}

Copyright reserved by the author(s).

This article is an open-access article distributed under the terms and conditions of the Creative Commons Attribution license (http://creativecommons.org/licenses/by/3.0/). 